\title{
Improving Disaster Readiness and the Response of Nurses in Saudi Arabia
}

\author{
Manal Al Harthi ${ }^{1,2}$ \\ Abdulellah Al Thobaity' \\ Mohammed Almalki ${ }^{1}$ \\ Waleed Al Ahmari' \\ 'Nursing Department, College of Applied \\ Medical Sciences, Taif University, Taif, \\ Saudi Arabia; ${ }^{2}$ King Faisal Medical \\ Complex, Ministry of Health, Taif, Saudi \\ Arabia
}

Correspondence: Abdulellah Al Thobaity Nursing Department, College of Applied Medical Sciences, Taif University,

P. O. Box I 1099, Taif, 21944, Saudi Arabia

Tel +966 12-727-2020

Email a.thobaity@tu.edu.sa
Introduction: Nurses in Saudi Arabia face several challenges in all phases of disaster nursing, such as the infancy of the specialty and a lack of education, preparedness, research, and expertise in both the clinical field and in academics. Overcoming these challenges will help both nurses and the development of the specialty itself in aspects such as policies and procedures, education, and research. Thus, the aim of this study was to explore strategies for improving disaster nursing in Saudi Arabia.

Methods: A cross-sectional study with a principal component analysis (PCA) was conducted to identify the factors affecting disaster nursing in Saudi Arabia. The sample of the study was Saudi Arabian nurses, as they are first-line responders in disasters and pandemics. Results: From 800 distributed questionnaires, 569 completed questionnaires were returned, for a response rate of $71 \%$. The findings of the PCA revealed two components that can be extracted from the data. The first is preparedness, which involves 13 items related to the actions that must be taken before a disaster occurs, with a loading range of 0.82 to 0.70 . The second factor is the action taken after a disaster occurs, and there are seven items with a loading range of 0.83 to 0.73 .

Conclusion: For improved disaster nursing, it is essential to develop evaluation tools, create specific nursing legislation for disaster situations, provide personal protective equipment to nurses to minimize the risk of infection, and encourage nurses by appreciating their efforts to minimize their stress level during a disaster. It is also important to make sufficient supplies and equipment available to nurses during a disaster and provide them with psychological support while acknowledging the importance of contact with their families and friends.

Keywords: disaster nursing, disaster preparedness, emergency nursing, Saudi Arabia

\section{Introduction}

Nurses play a significant role in disaster control and in minimizing the impact of a disaster on society, and this significance extends through all phases of a disaster. Before a disaster, nurses help identify potential risks and work with teams to reduce and prevent these risks via the creation of strategies and plans. Nurses also participate in the development of policies and guidelines related to disasters, ${ }^{1-6}$ as well as helping in preparedness activities, including education and training. ${ }^{7}$ During a disaster, nurses respond, either inside or outside of hospitals, by providing holistic care for the people who are impacted. ${ }^{8-10}$ After disasters, nurses work with other medical teams to ensure that hospitals recover from the disaster. Disaster nurses must use critical thinking skills to control the conditions of a disaster by utilizing the available resources, creating new strategies to deal with updates in the current situation, coordinating with other colleagues, and delegating tasks to others if 
needed, and when doing so does not interfere with being flexible and adapting to the situation. ${ }^{11}$

A review of the literature shows that disaster nursing in Saudi Arabia is facing specific challenges. First, it is still a rather new specialty, despite a recent increase in research and academic programs. ${ }^{2,10}$ This issue is reported worldwide, as a unified standard is needed to clarify nurses' roles during disasters. ${ }^{11-13}$ The lack of preparedness is another issue for nurses in Saudi Arabia, as an effective response requires adequate preparedness from both healthcare providers and health organizations. ${ }^{14,15}$ Fortunately, more efforts are being taken by the Saudi Arabian authorities to improve the country's disaster preparedness. ${ }^{16}$ In principle, all healthcare providers must be ready and well prepared in many aspects, from ensuring in-clinic provision of essential medical care that is distinct from the events of a disaster, ${ }^{17}$ to other non-clinical tasks, such as coordination, communication, and categorizing and prioritizing cases according the availability of resources. ${ }^{17-19}$ Third, formal and informal education in disaster nursing in Saudi Arabia are still not fully developed, and this might be related to the lack of educators and experts. ${ }^{1,2,20-22}$ Fourth, disaster nursing in Saudi Arabia lacks research and valid and reliable tools and scales. ${ }^{2,22}$ Finally, despite a description of nurses' roles in hospitals' disaster response plans, few emergency nurses understand their role to be the provision of surveillance, prevention, leadership, or psychological care during mass gatherings. Thus, nurses must participate in creating and updating disaster plans and in drills conducted inside the hospital to better understand their role. ${ }^{1,2,20,21,23}$ These challenges require exploring strategies for improving disaster nursing in Saudi Arabia. Such strategies will help in developing the specialty itself in multiple aspects, such as the development of policies and procedures for practice, education, and research. Thus, the aim of this study is to explore strategies for improving disaster nursing in Saudi Arabia.

\section{Method}

A cross-sectional study using principal component analysis (PCA) was utilized in this research. The population of this study was nurses in four main hospitals at Taif governance under the Saudi Arabia of ministry of health, and the sample included nurses who were first-line responders to the disaster of the current pandemic. The inclusion criteria for participants were at least a 3-year diploma in the specialty of disaster nursing and at least 1 year of experience in the field. Based on PCA, which requires a sample size $>100$, a non-random convenience sample was obtained through an open link survey.

A total of 800 questionnaires were distributed to four hospitals in Taif, after contact with the head nurses in each department. The items of the questionnaires were generated from published studies related to disaster nursing in Saudi Arabia that were discovered during a review to identify the most common challenges faced by nurses in disaster management. ${ }^{22}$ As a result, 70 items were generated. After deleting redundant items, integrating similar ones, and a review by experts in the field of disaster nursing, 40 items remained. The validity of this tool was checked in three phases. First, this instrument was created based on the literature review. Second, 40 items of the questionnaire were reviewed by experts in disaster nursing in terms of face validity and content validity, and finally, a PCA was conducted on these. The questionnaire consisted of two parts: The first part gathered the participants' demographic data and the second part involved 40 items related to the improvement of disaster nursing in Saudi Arabia. A 5-point Likert scale was used to measure the agreement of respondents on five points with the following choices: 1 for strongly disagree, 2 for disagree, 3 for neutral, 4 for agree, and 5 for strongly agree. Descriptive statistics and PCA using SPSS version 24 were used to analyze the data. ${ }^{24}$

Ethical approval was obtained from the IRB of the research department in the Directorate of Health Affairs at Taif governance (IRB registration number HAP-02T-067 with approval number 455 from 12/11/2020). There were no expected risks of injury, discomfort, or psychological or physical harm through involvement in this study. No consent was obtained from the participants, as submission of the electronic survey indicated their agreement to participate; after submission, only the authors of the study viewed the data. All participants were informed of the purpose of the study and that it was conducted in accordance with the Declaration of Helsinki.

The PCA protocol was adapted from Williams et $\mathrm{al}^{24}$ and involved the following: 1) The suitability of the data for PCA, which requires that the sample be more than 100 , must be assured as well as the suitability of the findings of Kaiser-Meyer-Olkin and Bartlett's test. 2) The method for extracting the factors was PCA, as it is the most commonly used and recommended method when no theory exists about the topic. 3) The criteria for extracting the factors were based on the values of eigenvalues, which 
must be more than 1 for the factor (any factor having less than 1 was excluded), and the results of cumulative percentage of variance should be above 50\%. 4) The method of rotation in this study was varimax, as it allows for the production of factors that are not correlated with each other. 5) Interpretation and naming of the extracted factors were based on the items that have loading on each factor. Each factor was labeled based on the common aspects of the loaded items.

\section{Results}

From 800 distributed questionnaires, 569 were returned, giving a response rate of $71 \%$. As shown in Table 1, the majority of participants were female $(82.2 \%)$, the male response was $17.6 \%$, and one participant did not disclose a gender $(0.2 \%)$. The majority of participants have a bachelor's degree (77.3\%). Higher diplomas represent $12.7 \%$, with $8.3 \%$ having master's degrees and $0.5 \%$ having doctoral degrees; those with unspecified qualifications represent $1.2 \%$. In terms of years of experience, $39 \%$ had of $5-10$ years, $26 \%$ had $10-15$ years, $21.8 \%$ had $1-5$ years, and $12.3 \%$ had $15-20$ years. In terms of age, the majority were $30-39$ years at $58 \%, 20-29$ years at $25.8 \%$ and $40-49$ years at $13 \%$; participants 50 years or above made up $3 \%$.

Using PCA as a method of extracting the factors and varimax for rotation, three factors were extracted from the

Table I Demographics Data

\begin{tabular}{|c|c|c|c|}
\hline & & Frequency & Percent \\
\hline \multirow[t]{3}{*}{ Gender } & Male & 100 & 17.6 \\
\hline & Female & 468 & 82.2 \\
\hline & Total & 568 & 99.8 \\
\hline \multirow[t]{6}{*}{ Qualification } & Higher diploma & 72 & 12.7 \\
\hline & Bachelor's degree & 440 & 77.3 \\
\hline & Master's degree & 47 & 8.3 \\
\hline & Doctoral degree & 3 & 0.5 \\
\hline & Others & 7 & 1.2 \\
\hline & Total & 569 & 100.0 \\
\hline \multirow[t]{5}{*}{ Experiences } & $\mathrm{I}-5$ years & 124 & 21.8 \\
\hline & $5-10$ years & 222 & 39.0 \\
\hline & $10-15$ years & 152 & 26.7 \\
\hline & 15-20 years & 70 & 12.3 \\
\hline & Total & 568 & 99.8 \\
\hline \multirow[t]{5}{*}{ Age } & 20-29 years old & 147 & 25.8 \\
\hline & 30-39 years old & 330 & 58.0 \\
\hline & 40-49 years old & 74 & 13.0 \\
\hline & 50 years or more & 17 & 3.0 \\
\hline & Total & 568 & 99.8 \\
\hline
\end{tabular}

data with total variances of $75 \%$, and each factor scored more than 1 in eigenvalue (details reported later in this section). The findings of the PCA indicated two components that could be extracted from the data after redundant and the cross-loading items were deleted; that is, from the original 40 items, 20 items remained after the PCA. Table 2 illustrates the loaded items for each factor, along with mean (M) and standard deviation (SD).

The first factor of strategies for the development of disaster nursing in Saudi Arabia is preparedness; this involved 13 items related to actions that must be taken before a disaster occurs, with loading from 0.82 to 0.70 . The eigenvalue for this component was 13.82 , and the variances value was $69.06 \%$. The items with a strong loading $(>0.80)$ were "Develop evaluation tool in disaster nursing" and "Create specific legislation on emergencies and disasters for nurses" In terms of mean values, the top strategies for improving disaster nursing preparedness were "Focus on hands-on experience in real situations and drills for nurses," with $\mathrm{M}=4.03$ and $\mathrm{SD}=0.87$, and "Emphasize creating a clear communication strategy to deal with disaster situations, to be known by nurses for reacting to extraordinary situations," with $M=4.10$ and $\mathrm{SD}=0.85$.

The second factor pertains to actions taken after a disaster occurs. This factor comprised seven items with a loading range of 0.83 to 0.73 . The eigenvalue for this component was 1.36 , and the variance value was $6.84 \%$. There were four items with a strong loading of more than 0.80 'There were four as follows: "Provide enough personal protective equipment for nurses to minimize the risk of infection while dealing with biological disasters," "Motivate the nurses by appreciating their efforts to minimize their stress level due to disaster incidence," "Provide enough supplies, equipment, and machines to help nurses to perform their role during disasters," and "Provide psychological support for nurses during pandemics, by maintain a suitable environment to work and not to ignore the importance of contact with their families and friends". In terms of mean values, the top strategies for improving disaster nursing during the response phase were as follows: "Provide enough personal protective equipment for nurses to minimize the risk of infection while dealing with biological disasters," with $\mathrm{M}=4.29$ and $\mathrm{SD}=0.92$; "Provide enough supplies, equipment, and machines to help nurses perform their role during disasters," with $\mathrm{M}=4.29$ and $\mathrm{SD}=0.92$; "Motivate the nurses by appreciating their efforts to minimize their stress level due to 
Table 2 Principal Component Analysis (PCA) Findings

\begin{tabular}{|c|c|c|c|c|}
\hline \multirow[t]{2}{*}{ Items } & \multicolumn{2}{|l|}{ Factor } & \multicolumn{2}{|c|}{ Descriptive } \\
\hline & $\mathbf{I}$ & 2 & $\mathbf{M}$ & SD \\
\hline Develop evaluation tool in disaster nursing. & 0.82 & & 3.96 & 0.89 \\
\hline Create specific legislation for disaster nursing & 0.80 & & 4.00 & 0.84 \\
\hline Conduct frequent evaluation for nurses' performance. & 0.79 & & 3.89 & 0.93 \\
\hline Enhance the evidence-based practice required more contributions. & 0.78 & & 4.00 & 0.88 \\
\hline Focus on hands-on experience and drills. & 0.77 & & 4.03 & 0.87 \\
\hline Presence of scientific journals in the disaster nursing field & 0.75 & & 3.96 & 0.89 \\
\hline $\begin{array}{l}\text { Clarify the documentation process of nursing care for disaster victims and document accurate information, } \\
\text { even if nothing is done. }\end{array}$ & 0.75 & & 3.91 & 0.91 \\
\hline Illustrate the access to the educational resources related to disaster nursing. & 0.74 & & 3.98 & 0.89 \\
\hline Include disaster education in undergraduate nursing curriculum. & 0.73 & & 3.97 & 0.90 \\
\hline A clear communication strategy to follow in case of disastrous incidence. & 0.72 & & 4.10 & 0.85 \\
\hline Developing solutions for recurrent ethical dilemmas during disaster events. & 0.72 & & 4.00 & 0.84 \\
\hline Assess the preparedness level for nurses periodically. & 0.72 & & 4.02 & 0.86 \\
\hline Maintain the nurses safety during disaster. & 0.70 & & 4.00 & 0.89 \\
\hline Provide enough personal protective equipment's. & & 0.83 & 4.29 & 0.92 \\
\hline Motivate the nurses by appreciating their efforts to minimize their stress level due to disaster incidence. & & 0.82 & 4.24 & 0.94 \\
\hline Provide enough supplies, equipment, and machines. & & 0.82 & 4.29 & 0.92 \\
\hline $\begin{array}{l}\text { Provide psychological support for nurses during pandemics, and it is important to get family support to work } \\
\text { during disaster. }\end{array}$ & & 0.81 & 4.18 & 0.95 \\
\hline Consider financial incentives to motivate the nurses to work during pandemics. & & 0.77 & 4.23 & 1.01 \\
\hline Assign a qualified leader who is able to manage nurses' conflicts. & & 0.73 & 4.17 & 0.90 \\
\hline Minimize the workload on nurses by assign health assistance. & & 0.73 & 4.15 & 0.91 \\
\hline Eigenvalue & 13.81 & 1.36 & - & - \\
\hline Variations \% & $69.06 \%$ & $6.84 \%$ & - & - \\
\hline
\end{tabular}

disaster incidence," with $\mathrm{M}=4.24$ and $\mathrm{SD}=0.94$; and "Consider financial motivation and support for nurses during pandemic response," with $\mathrm{M}=4.23$ and $\mathrm{SD}=1.01$.

\section{Discussion}

Disasters have a negative impact on healthcare institutions, including hospitals, primary health care centers, and emergency departments. ${ }^{11,25}$ As nurses play a major role in disaster management prior to, during, or after a disaster, they face several challenges, as has been reported by studies done in Saudi Arabia and around the word. ${ }^{1,2,4,6,10,22,26,27}$ After using a rigorous process of discovering items that identify strategies for the development of disaster nursing in Saudi Arabia, seven strategies were explored.

\section{Strategy I: Develop Evaluation Tools for Use in Disaster Nursing}

In disaster nursing, there are a limited number of evaluation tools available that have been tested to confirm their validity and reliability. ${ }^{2,10,22}$ Moreover, some of the tools that are available have not been tested psychometrically. 
A checklist for evaluating nurses' performances, identifying educational needs, helping to update disaster policies and plans, and measuring the level of preparedness is essential in terms of disaster nursing in Saudi Arabia. However, previous studies have indicated that the available checklist tools for evaluating a hospital's readiness do not include all necessary aspects, such as a disaster plan, incident command system, safety, quality, communication, education, decontamination, triage, evacuation, knowledge, competences, evidence-based practice, psychological support, and surge capacity. ${ }^{28}$ Thus, hospitals need to include all of these aspects in the checklist and incorporate it into their disaster strategy. Despite the fact that "disaster nursing specialty" has a broad meaning with many related dimensions and different phases, most of the current tools in this field focus on the readiness phase. ${ }^{13,29,30}$ It is crucial to develop a new tool using disaster expertise that involves the assessment of all disaster phases, is compatible with disaster planning in each hospital and education program, and involves the real task of nurses. ${ }^{2,30}$

\section{Strategy 2: Create Specific Legislation for Nurses on Emergencies and Disasters}

Although emergency nurses can quickly adapt to the chaos of emergency departments on regular days, ${ }^{26,31,32}$ when a disaster hits, the unusual situation will require nurses to respond even if doing so will put them at risk. Thus, nurses will face many ethical dilemmas due to a lack of knowledge if they are not able to deal with a disaster. Additionally, the people who are responsible for creating disaster plans and related educational courses ignore ethical considerations. ${ }^{17}$ Therefore, it is recommended that courses be designed to teach nurses how to apply their ethical code during different disaster scenarios, especially triage, and that a national guideline be established to help nurses make appropriate decisions. This is crucial for nurses in Saudi Arabia, as it will enhance their ability to make appropriate decisions during emergency situations and add disaster-related ethical and legal content to nursing curricula. Furthermore, nurses must be made aware of national and international legislation, including what procedures they are allowed to perform, to guide and keep them safe while treating their patients under disaster conditions. Standardized ethical laws specialized for nursing practice must be established to help nurses react correctly in disaster situations. Another priority should be to conduct more research related to the application of ethical codes. $^{33}$

\section{Strategy 3: Focus on Hands-on Experience with Real Situations and Drills for Nurses}

Nurses will not become skillful in the treatment of disaster victims unless they are engaged in real cases, simulations, or drills. Other exercises, such as tabletop and theoretical lectures, would not be as effective due to the lack of a practical component that has a good chance of improving knowledge and leadership skills. ${ }^{34}$ To increase nurses' confidence and provide a high quality of care during disasters, frequent disaster courses for nurses, involving realistic scenarios and practical experience, should be provided. It is essential to improve nurses' knowledge by encouraging self-learning using educational smart phone or laptop programs related to disasters. ${ }^{1}$ Additionally, nurses must be given access to relevant databases where they can find necessary information. ${ }^{1}$ Moreover, it is suggested that a cross-training program be conducted in which staff who work in an area that rarely faces a disaster go to an area where disasters are more common to gain knowledge and experience.

\section{Strategy 4: Emphasize Creating a Clear Communication Strategy to Deal with Disaster Situations to Be Used by Nurses Reacting to Extraordinary Situations}

One of the necessary disaster plan components is the communication process. When a disaster strikes, it is expected that nurses will respond confidently and competently to a disaster without delay, deliver different types of services to victims, solve clinical and operational problems accurately, communicate effectively, and manage resources wisely. ${ }^{35}$ Creating a standardized and comprehensive disaster plan could facilitate the communication process for nurses and other health practitioners within the institution and provide a safe work environment. ${ }^{36}$ In Saudi Arabia, studies have emphasized the importance of assessing the current defects in the education process regarding pre-hospital and inside-hospital communication, orienting the staff to it, and conducting more research needed to find a new protocol to facilitate communication. ${ }^{2,14,15}$ 
Strategy 5: Provide Enough Personal Protective Equipment for Nurses to Minimize the Risk of Infection While Dealing with Biological Disasters

Personal protective equipment (PPE), such as gloves, goggles, face masks, and gowns, is necessary for nurses when dealing with various types of disasters, such as biological, chemical, and radiological. A lack of PPE or its improper use could lead to transmission of infection or contamination to nurses and patients. ${ }^{21,37}$ Also, the availability of resources increases nurses' potential willingness to respond to a disaster, with the most important being access to PPE, followed closely by the availability of vaccinations. In addition, the literature indicates that nurses who used PPE during the COVID-19 pandemic are more familiar with its proper use, but more knowledge is needed on the decontamination process. ${ }^{20,21,38}$

\section{Strategy 6: Motivate Nurses by Appreciating Their Efforts to Minimize Their Stress Level During Disasters}

In some situations, nurses are obligated to choose one patient another, having the responsibility to give care or save a life based on the available resources, as in times of war. Such a heavy responsibility can cause great remorse and stress. Additionally, attendance at the death of a patient affected by the disaster is certain to have a negative effect on a nurse's psychological state. ${ }^{39}$ The resulting stress level could have a negative consequence on nurses' health, such as sleep disturbance, respiratory and cardiovascular problems, post-traumatic syndromes, drug abuse, or even suicidal thoughts. ${ }^{39}$ In disastrous events, nurses will find themselves working under extreme stress and in uncomfortable circumstances. One study conducted in Indonesia explored the causes of stress due to disaster ${ }^{40}$ and found three applicable techniques that could be useful for nurses. First, nurses must support and motivate each other. Second, self-learning about the types of disasters may increase knowledge and decrease stress levels. Third, nurses should follow appropriate instructions regarding protection and safety, such as infection control precautions. Also, one of the greatest sources of motivation for nurses is their family support, which plays a significant role in minimizing their stress levels. Thus, it is recommended that resources be provided to establish a special program to deal with nurses who have psychological or physical problems due to working under stress in a disaster, and this program should be included in disaster plans. ${ }^{39}$ It is also suggested that focus should be placed on increasing the financial motivation for nurses, and appreciating their efforts during a disaster could minimize stress in such situations.

\section{Strategy 7: Provide Enough Supplies, Equipment, and Machines to Help Nurses Perform Their Role}

One of the basic components of surge capacity is to prepare each hospital to receive disaster victims through the provision of supplies and equipment. One of the most common challenges faced by hospital administrators is the high demand for the same supplies and machines. ${ }^{41}$ Due to the high patient flow during disasters and an increase in the nurse-to-patient ratio, nurses need more resources to do their work successfully. It is recommended that the technologies used in nursing come with high quality and frequent training as well as routine maintenance. The benefits of this, such as maintaining quality and safety, lowering costs, and reducing medical errors, are emphasized in the nursing literature. ${ }^{42}$

\section{Conclusion}

There are two major strategies for improving the readiness of nurses for disasters: develop evaluation tools for use in disaster nursing, emphasize the importance of clear communication, and create specific legislation for disaster nursing. In addition, there are four strategies for improving responses to disaster: provide enough PPE to nurses to minimize the risk of infection, motivate nurses by appreciating their efforts to minimize their stress level, provide enough supplies and equipment for nurses to perform their role during a disaster, and provide psychological support for nurses by maintaining a suitable environment to work and not ignoring the importance of contact with their families and friends.

\section{Acknowledgments}

We greatly appreciate Taif University for support of this study through Taif University Researchers Supporting Project number (TURSP-2020/237), Taif University, Taif, Saudi Arabia. The authors also express their gratitude to all participants who gave their valuable time to this project. 


\section{Disclosure}

The authors declared that they have no conflicts of interest in this work.

\section{References}

1. Al Thobaity A, Plummer V, Innes K, Copnell B. Perceptions of knowledge of disaster management among military and civilian nurses in Saudi Arabia. Australas Emerg Nurs J. 2015;18 (3):156-164. doi:10.1016/j.aenj.2015.03.001

2. Al Thobaity A, Williams B, Plummer V. A new scale for disaster nursing core competencies: development and psychometric testing. Australas Emerg Nurs J. 2016;19(1):11-19. doi:10.1016/j. aenj.2015.12.001

3. Alyasin A, Douglas C. Reasons for non-urgent presentations to the emergency department in Saudi Arabia. Int Emerg Nurs. 2014;22 (4):220-225. doi:10.1016/j.ienj.2014.03.001

4. Arbon P, Ranse J, Cusack L, et al. Australasian emergency nurses' willingness to attend work in a disaster: a survey. Australas Emerg Nurs J. 2013;16(2):52-57. doi:10.1016/j.aenj.2013.05.003

5. Filmer LB, Ranse J. Who is my leader? A case study from a hospital disaster scenario in a less developed country. Australas Emerg Nurs J. 2013;16(4):170-174. doi:10.1016/j.aenj.2013.08.004

6. Lenson S, Ranse J, Cusack L. Industrial considerations for nurses responding to disasters. Australas Emerg Nurs J. 2011;14:S28. doi:10.1016/j.aenj.2011.09.070

7. Loke AY, Guo C, Molassiotis A. Development of disaster nursing education and training programs in the past 20 years (2000-2019): a systematic review. Nurse Educ Today. 2021;99:104809. doi:10.1016/j.nedt.2021.104809

8. Setyawati A-D, Lu -Y-Y, Liu C-Y, Liang S-Y. Disaster knowledge, skills, and preparedness among nurses in Bengkulu, Indonesia: a descriptive correlational survey study. J Emerg Nurs. 2020;46 (5):633-641. doi:10.1016/j.jen.2020.04.004

9. Younos TB, Hasan MK, Nasreen M. Are nurses ready? Bangladeshi nurses' perceived preparedness for disasters: a mixed-methods approach. Int J Disaster Risk Reduct. 2021;58:102195. doi:10.1016/ j.ijdrr.2021.102195

10. Al Thobaity A, Plummer V, Williams B. What are the most common domains of the core competencies of disaster nursing? A scoping review. Int Emerg Nurs. 2017;31:64-71. doi:10.1016/j. ienj.2016.10.003

11. Powers R, Daily E. International Disaster Nursing. Cambridge University Press; 2010.

12. Zarea K, Beiranvand S, Sheini-Jaberi P, Nikbakht-Nasrabadi A. Disaster nursing in Iran: challenges and opportunities. Australas Emerg Nurs J. 2014;17(4):190-196. doi:10.1016/j.aenj.2014.05.006

13. Langan JC, Lavin RP, Griffin AR, Veenema TG, Dobalian A. From brainstorming to strategic plan: the framework for the society for the advancement of disaster nursing: a work in progress. Nurs Adm $Q$. 2019;43(1):84-93. doi:10.1097/NAQ.0000000000000335

14. Al Thobaity A, Alamri S, Plummer V, Williams B. Exploring the necessary disaster plan components in Saudi Arabian hospitals. Int J Disaster Risk Reduct. 2019;41:101316. doi:10.1016/j. ijdrr.2019.101316

15. Alzahrani F, Kyratsis Y. Emergency nurse disaster preparedness during mass gatherings: a cross-sectional survey of emergency nurses' perceptions in hospitals in Mecca, Saudi Arabia. BMJ Open. 2017;7 (4):e013563. doi:10.1136/bmjopen-2016-013563

16. Al-Wathinani AM, Alakeel A, Alani AH, et al. A cross-sectional study on the flood emergency preparedness among healthcare providers in Saudi Arabia. Int J Environ Res Public Health. 2021;18 (3):1329. doi:10.3390/ijerph18031329
17. Schultz CH, Koenig KL, Whiteside M, Murray R. Development of national standardized all-hazard disaster core competencies for acute care physicians, nurses, and EMS professionals. Ann Emerg Med. 2012;59(3):196-208.e1. doi:10.1016/j.annemergmed.2011.09.003

18. Mani ZA, Kuhn L, Plummer V. Common domains of core competencies for hospital health care providers in armed conflict zones: a systematic scoping review. Prehosp Disaster Med. 2020;35 (4):442-446. doi:10.1017/S1049023X20000503

19. Al Thobaity A. Exploring Disaster Nursing Core Competencies and Roles in Kingdom of Saudi Arabia (KSA). Monash University; 2016.

20. Felemban EM, Youssef HA, Al Thobaity A. Factors affecting the decontamination process in hospitals in Saudi Arabia. Risk Manag Healthc Policy. 2021;14:357. doi:10.2147/RMHP.S295262

21. Al Thobaity A, Alshammari F. Nurses on the frontline against the COVID-19 pandemic: an integrative review. Dubai Med J. 2020;3 (3):87-92. doi:10.1159/000509361

22. Al Harthi M, Al Thobaity A, Al Ahmari W, Almalki M. Challenges for nurses in disaster management: a scoping review. Risk Manag Healthc Policy. 2020;13:2627-2634. doi:10.2147/RMHP.S279513

23. Brinjee D, Al Thobaity A, Almalki M, Alahmari W. Identify the disaster nursing training and education needs for nurses in Taif City, Saudi Arabia. Risk Manag Healthe Policy. 2021;14:2301-2310. doi:10.2147/RMHP.S312940

24. Williams B, Onsman A, Brown T. Exploratory factor analysis: a five-step guide for novices. Australas J Paramed. 2010;8(3): 79-94. doi:10.33151/ajp.8.3.93

25. Alharthi S, Al-Moteri M, Plummer V, Al Thobiaty A, eds. The Impact of COVID-19 on the Service of Emergency Department. Healthcare; Multidisciplinary Digital Publishing Institute; 2021.

26. Enns CL, Sawatzky JA. Emergency nurses' perspectives: factors affecting caring. J Emerg Nurs. 2016;42(3):240-245. doi:10.1016/j. jen.2015.12.003

27. Hu Y, Hu J, Li L, Zhao B, Liu X, Li F. Development and preliminary validation of a brief nurses' perceived professional benefit questionnaire (NPPBQ). BMC Med Res Methodol. 2020;20(1):18. doi:10.1186/s12874-020-0908-4

28. Nekoie-Moghadam M, Kurland L, Moosazadeh M, Ingrassia PL, Della Corte F, Djalali A. Tools and checklists used for the evaluation of hospital disaster preparedness: a systematic review. Disaster Med Public Health Prep. 2016;10(5):781-788. doi:10.1017/dmp.2016.30

29. Al Khalaileh MA, Bond AE, Beckstrand RL, Al-Talafha A. The disaster preparedness evaluation toolC: psychometric testing of the classical Arabic version. $J$ Adv Nurs. 2010;66(3):664-672. doi:10.1111/j.1365-2648.2009.05208.x

30. Garbutt SJ, Peltier JW, Fitzpatrick JJ. Evaluation of an instrument to measure nurses' familiarity with emergency preparedness. Mil Med. 2008;173(11):1073-1077. doi:10.7205/MILMED.173.11.1073

31. Djalali A, Castren M, Khankeh H, et al. Hospital disaster preparedness as measured by functional capacity: a comparison between Iran and Sweden. Prehosp Disaster Med. 2013;28(5):454. doi:10.1017/ S1049023X13008807

32. Alsharari AF, Abu-Snieneh HM, Abuadas FH, et al. Workplace violence towards emergency nurses: a cross-sectional multicenter study. Australas Emerg Care. 2021. doi:10.1016/j.auec.2021.01.004

33. Agazio J, Goodman P. Making the hard decisions: ethical care decisions in wartime nursing practice. Nurs Outlook. 2017;65(5s):S92S99. doi:10.1016/j.outlook.2017.06.010

34. Stanley S, Wolanski TAB. Designing and Integrating a Disaster Preparedness Curriculum. Sigma Theta Tau; 2015.

35. Smith GP, Wenger D. Sustainable disaster recovery: operationalizing an existing agenda. In: Handbook of Disaster Research. Springer; 2007:234-257.

36. Couig MP, Gable A, Griffin A, et al. Progress on a call toa. Nurs Adm Q. 2017;41(2):112-117. doi:10.1097/NAQ.0000000000000226 
37. Gordon C, Thompson A. Use of personal protective equipment during the COVID-19 pandemic. Br J Nurs. 2020;29(13):748-752. doi:10.12968/bjon.2020.29.13.748

38. AlQurash AA, Al Thobaity A, Al Moteri MO, Almalki M, AlAhmari WA. The experiences of emergency nurses during the Covid-19 crisis: factor analysis. Health Notions. 2020;4(7):211-221. doi: $10.33846 / \mathrm{hn} 40703$

39. Sandifer PA, Walker AH. Enhancing disaster resilience by reducing stress-associated health impacts. Front Public Health. 2018;6:373. doi:10.3389/fpubh.2018.00373
40. Windarwati HD, Ati NAL, Paraswati MD, et al. Stressor, coping mechanism, and motivation among health care workers in dealing with stress due to the COVID-19 pandemic in Indonesia. Asian $J$ Psychiatr. 2021;56:102470. doi:10.1016/j.ajp.2020.102470

41. AlAssaf W. Challenges in pandemic disaster preparedness: experience of a Saudi academic medical center. Disaster Med Public Health Prep. 2020;1-5. doi:10.1017/dmp.2020.268

42. Powell-Cope G, Nelson AL, Patterson ES. Patient care technology and safety. In: Patient Safety and Quality: An Evidence-Based Handbook for Nurses; 2008.

\section{Publish your work in this journal}

Risk Management and Healthcare Policy is an international, peerreviewed, open access journal focusing on all aspects of public health, policy, and preventative measures to promote good health and improve morbidity and mortality in the population. The journal welcomes submitted papers covering original research, basic science, clinical \& epidemiological studies, reviews and evaluations, guidelines, expert opinion and commentary, case reports and extended reports. The manuscript management system is completely online and includes a very quick and fair peer-review system, which is all easy to use. Visit http://www.dovepress.com/testimonials.php to read real quotes from published authors. 